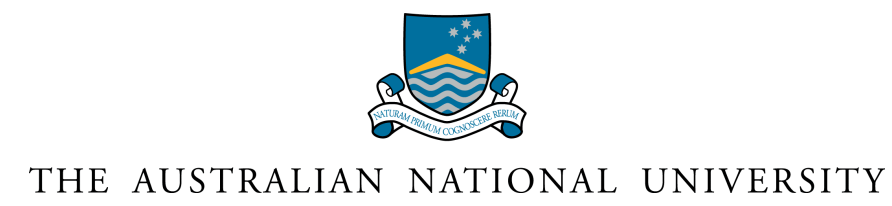

Working Paper Series in Finance 00-13

\title{
MODELLING THE BEHAVIOUR OF THE NEW ISSUE MARKET
}

\author{
Tim Brailsford \\ Richard Heaney \\ Jing Shi \\ School of Finance and Applied Statistics \\ Australian National University
}

JEL Classification

Keywords

Last revision date:

Contact author:
G10

IPOs; Time-series; New issues market; Momentum April 2001

Dr Richard Heaney

School of Finance and Applied Statistics

Faculty of Economics and Commerce

Australian National University

Canberra 0200 AUSTRALIA

Telephone: 0261254726 (International +61 26125 4726)

Facsimile: 0261255005 (International +61 26125 5005)

Email: Richard.Heaney@anu.edu.au

The working paper series is for manuscripts in draft form. Comments are welcome and should be sent to the contact author. Please do not quote without permission.

(C) Copyright 2001 T.J. Brailsford, R.A. Heaney and J. Shi 


\title{
MODELLING THE BEHAVIOUR OF THE NEW ISSUE MARKET
}

\author{
Tim Brailsford, Richard Heaney and Jing Shi \\ School of Finance and Applied Statistics \\ Australian National University
}

\begin{abstract}
This paper analyses the time-series behaviour of the new issue market in the context of an equilibrium model of demand and supply for IPOs. The model produces testable equations examining the relationship between the number of new issues and the average level of under-pricing, and also incorporates the impact of general market conditions. The model proposes that, first, serial correlation will be evident in both the number of new issues and the average level of under-pricing. Second, market conditions will affect both the number of new issues and the average level of underpricing. Finally, there will be interactions between the number of new issues and the average level of under-pricing. The key characteristic of the model is the explicit recognition of the delay between the firm's decision to list and the actual listing date. The model is tested using a monthly IPO time-series over the last forty years. The empirical results are generally consistent with the model's predictions.
\end{abstract}

Acknowledgements: We express our gratitude to Jay Ritter for providing the data used in the study. We thank Trevor Breusch and John Powell for their helpful comments and suggestions on earlier versions of the paper and we thank the participants at the 13th Annual Australasian Finance \& Banking Conference, Sydney, for their comments and suggestions. Appreciation is also extended to the Australian Research Council for funding (grant reference number FRGS S62 040 16). 


\section{INTRODUCTION}

Initial public offerings (IPOs) are a major source of equity funds and can have a significant influence on the stock market as evidenced by the recent internet bubble arising from 'new economy floats'. It is now well documented that IPOs exhibit under-pricing on average, with the subscription price generally set below the first day trading price. More recently, studies have shown that under-pricing tends to be clustered across time and that these periods coincide with a large volume of new issues. This evidence suggests that IPO markets follow cycles with the observance of 'hot' and 'cold' periods (eg. Ritter 1984; Helwge and Liang 1996; James and Kieschnick 1997; Lowry and Schwert 2000). In brief, a hot issue market is usually characterised by an increase in the number of unseasoned offerings, severe underpricing and frequent over-subscription (Ritter, 1984).

There have been several attempts to explain the existence of hot issue IPO markets. However, the explanations have generally not proved to be satisfactory in fully accounting for the observed market behaviour. Existing explanations focus on specific characteristics that are either demand or supply-side driven. In this paper, we develop a simple model of supply and demand that incorporates economic conditions. The advantage of such an approach is that it provides an equilibrium framework in which to consider jointly under-pricing and new issue volume. Prior work has generally only considered either under-pricing or new issue volume independently. This approach allows us to focus on the time series behaviour of both the under-pricing and the level of IPO issues. The model is tested using a monthly time-series of new issues, spanning the last forty years. The results are supportive of the model's predictions. 
The paper is organised as follows. Section 2 presents a review of the literature and theory development, while the data series are described in Section 3. The results are reported in Section 4 and a summary is provided in Section 5.

\section{THEORY DEVELOPMENT}

\subsection{Prior Literature}

The IPO market is often characterised by periods of high ('hot') and low ('cold') intensity of activity. This activity may be viewed either in terms of a volume measure such as the number of IPO issues per period (Loughran et al. 1994) or a periodic under-pricing measure (Ibbotson and Jaffe 1975; Ritter 1984).

Ibbotson and Jaffe (1975) first document that the degree of IPO under-pricing is cyclical and concentrated in particular periods. Using US data for the period of 19601982, Ritter (1984) documents a hot issue market in 1980 which he attributes to the boom in small natural resource stocks. Ritter argues that this feature is consistent with a risk and return trade-off with the substantial increase in small high-risk issues being accompanied by greater levels of under-pricing. Small natural resource stocks are more difficult to value, suffer from increased information asymmetry and have higher business risk. The signalling arguments of Allen and Faulhaber (1989) also provide some support for hot periods being associated with increases in risk.

A further explanation for cycles in IPO under-pricing involves under-writer monopsony power (Ritter 1984). In this hypothesis, under-writers benefit from bringing firms onto the market below their market price because it helps to ensure full subscription and reduces the costs of promoting and marketing the issue. Moreover, 
the under-writers can keep favoured clients contented through selective allocation, and this in turn generates subsequent profitable business. However, competition among underwriters will limit the extent of deliberate under-pricing. Nevertheless, there may be certain periods where under-writers can exert greater monopsony power (Loughran and Ritter 2000).

A final argument is provided by Ritter (1991) who posits investor over-reaction as an explanation of under-pricing. This argument has become formalised through Rajan and Servaes (1997) who suggest that investors utilise positive feedback strategies and exploit information spillovers in the IPO market. Hot periods are observed due to momentum. Suppose that initial IPO returns provide information on expected growth of the underlying firm. In this framework, current under-pricing would lead to increased growth expectations and improved investor sentiment. Moreover, during periods of high volume, there is information spillover reducing the costs of information search on each issue. As a result, firms contemplating a public float interpret the high initial returns in the market as a signal that they can now raise more money than they first thought. With the encouragement of under-writers, momentum builds in the market. Lowry and Schwert (2000) suggest that these effects take time to build due to the institutional lags induced through regulatory requirements and bookbuilding activities. This induced lag manifests itself through induced autocorrelation in the under-pricing series.

Clearly, the above arguments have linkages to new issue volume. Evidence shows that 'hot' cycles also exist in IPO volume (Ibbotson et al. 1994). Further, Ibbotson et al. (1994) describe both the level of under-pricing and the IPO volume as persistent 
processes where the current period level of under-pricing and IPO volume appear to be good predictors of the future level of under-pricing and IPO volume, respectively.

Lowry (1999) suggests three explanations for the observed cycles in new issue volume. First, changes in aggregate demand for capital over time influence the supply of IPOs. That is, economic forces change a firm's demand for capital and there are periods when the aggregated demand across firms can become concentrated. The consequent response is a variation in the supply of capital through the new issue market. Second, changes in adverse selection costs of issuing equity may be periodic. Declines in adverse selection costs of issuing equity may be created through a decrease in market-wide information asymmetry. Finally, variation in investor optimism may also influence the firm's decision to issue. During periods of high optimism, investors may be willing to pay relatively more for IPOs inducing an increase in supply of capital.

The link between new issue volume and under-pricing is probably best described by Ibbotson et al. (1988) who demonstrate significant positive correlation between the annual series in current year initial returns and the subsequent year's IPO volume of 0.49. On inspection of monthly data, they suggest a lag period of 6-12 months and it is this feature that we attempt to formally model. Lowry and Schwert (2000) list a number of intuitive explanations for the interaction between under-pricing and the volume of new issues. As noted above, Lowry and Schwert conclude that the period between the decision to issue and final issue date appears to explain the incidence of serial correlation in under-pricing and the number of IPOs (per month). Hence, the 
signal contained in current under-pricing leads to decisions to issue and therefore current under-pricing leads future volume

Economic variables have also been proposed to explain the cyclical behaviour observed in IPO markets. Loughran et al. (1994) argue that there is a positive relationship between the inflation adjusted stock index and IPO volume. Rees (1997) provides evidence that the stock market level predicts both the value and volume of IPOs in the UK. Further, Choe et al. (1993) identify a positive relationship between the number of seasoned equity issues and economic activity, arguing that firms will issue equity in boom periods when the costs of information asymmetry (as a proportion of investment returns) are lower, as argued above. This result should also have applicability to unseasoned issues given the presence of information asymmetry in the IPO market. Thus the existence of hot and cold IPO markets may be a simple economic phenomenon such that hot markets are most apparent when equity markets are booming and cold markets are observed when equity markets are depressed. Supporting evidence is found in the South Korean market where the hot issue market of 1988 coincided with a major bull run in the stock market (Ibbotson and Ritter, 1995).

The above explanations focus on either factors that induce changes in demand for new issues or factors that influence changes in the supply of new issues. However, the IPO market, like any other market, is subject to the natural laws of both demand and supply. Hence, an approach is required that jointly considers both demand and supplyside factors. In the next section, we present such a model. 


\subsection{A Time-series Model of IPOs}

In this section, a model is developed that provides an explanation for the time-series behaviour of average under-pricing per month and the number of IPOs. The model incorporates the role of economic conditions and allows for the possibility of lead/lag interactions.

We commence with a discrete period model. ${ }^{1}$ The basic premise begins with the standard approach that there is a market equilibrium level of under-pricing and a market equilibrium number of IPOs at any particular time that is determined by the interaction of the forces of supply and demand. Further, it is assumed that the IPO market is competitive.

The demand for IPOs is assumed to be an increasing function of the level of underpricing (eg. Rock 1986; Firth 1997). Although it is generally accepted that demand for shares is highly elastic it could be argued that, given few substitutes for IPO firms, the demand for shares in any one IPO may be less elastic. Thus a greater level of IPO under-pricing suggests greater initial profits accruing to investors on average, and hence greater demand for new issues. In short, the greater the level of IPO underpricing, the greater the demand for IPOs.

In a new issue, investors are asked to either indicate their interest in a firm commitment contract or alternatively bid for a quantity of new shares in a best efforts contract. $^{2,3}$ The expected subscription price and expectations about the level of under-

\footnotetext{
${ }^{1}$ Silberberg (1981) and Enders (1995) provide useful descriptions of this model.

${ }^{2}$ The relative frequency of best efforts offerings has decreased over the 1990s.
} 
pricing are formed prior to the actual listing of the new stock. We assume a linear demand curve, and hence investor demand can be given by:

$$
\mu_{t}=\alpha+\beta N_{t}^{d}+\eta_{1 t}
$$

In (1), the level of under-pricing expected at time $t\left(\mu_{t}\right)$ is a function of a constant term $(\alpha)$ and the number of IPOs at time $\mathrm{t}\left(N_{t}^{d}\right)$ scaled by a constant $(\beta)$ indicating the sensitivity of demand to the number of IPOs (where $\beta>0$ ). Residual demand effects are captured by the error term $\left(\eta_{1 t}\right)$.

Given rational behaviour by firm managers, it could be argued that the greater the level of under-pricing, the lower the supply of IPOs. Privately held firms would generally prefer no under-pricing on average as owners are then fully compensated for their sale of equity in the firm (Loughran and Ritter 1995). However, it is known that IPO issuers cannot act instantaneously since there is often a three to six-month period between the commencement of the IPO process and the consequent listing date (eg. Lipman 1997). When the decision is made to go public, the available information set includes the current level of under-pricing, the number of IPOs currently on issue and the current economic/equity market conditions. This information set is used in forming predictions about the future condition of the IPO market at the listing date (Choe et al. 1993; Loughran et al. 1994). Hence, given the inability of issuers to respond immediately to market conditions, the number of IPOs in the current period will reflect the information set in prior periods. Following this argument, a linear supply curve takes the following form:

\footnotetext{
${ }^{3}$ See Ritter (1998) for a detailed description of new issue contracts.
} 


$$
N_{t}^{s}=\phi+\sum_{i=1}^{j} \gamma_{i} \mu_{t-i}+\sum_{i=1}^{k} \varphi_{i} N_{t-i}^{s}+\sum_{i=1}^{l} \delta_{i} \chi_{t-i}+\eta_{2 t}
$$

The number of IPOs supplied at time t $\left(N_{t}^{s}\right)$ is a function of a constant term $(\phi)$, the level of under-pricing observed in previous periods $\left(\mu_{t-i}\right)$ scaled by $\gamma_{1}$ (the sensitivity of supply to the level of under-pricing), the number of IPOs observed in previous periods $\left(N_{t-i}\right)$ scaled by $\varphi_{1}$ (the sensitivity of supply to the number of IPOs) and $\chi_{t-i}$ which is a measure of economic conditions, scaled by the sensitivity of supply to economic conditions $\left(\delta_{t}\right)$. Residual supply effects are captured with the error term $\left(\eta_{2 t}\right)$.

Both IPO investors and issuers are assumed to be price takers. Investors (IPO buyers) are assumed to be able to act immediately in their investment decisions while issuers (IPO sellers) act with a time lag during which various activities are undertaken to fulfil the legal requirements of the issue and promote the issue. Based on the law of one price, the "reduced form" demand equation consists of:

$$
\mu_{t}=(\alpha+\beta \phi)+\sum_{i=1}^{j} \beta \gamma_{i} \mu_{t-i}+\sum_{i=1}^{k} \beta \varphi_{i} N_{t-i}^{s}+\sum_{i=1}^{l} \beta \delta_{i} \chi_{t-i}+\left(\eta_{1 t}+\beta \eta_{2 t}\right)
$$

That is, equation (3) is based on underlying models of demand and supply detailed in equations (1) and (2).

It is not possible to specify the actual form of the demand or supply equation as this is an empirical question. Nevertheless there are a number of predictions generated by the model. A key prediction is the existence of auto-correlation, consistent with the observations of Ibbotson et al. (1994) and Lowry and Schwert (2000). A further implication concerns the role of economic/market conditions for both under-pricing 
and volume, consistent with Choe et al. (1993) and Loughran et al. (1994). Finally, the model also allows for the possibility of interaction between the average level of underpricing and the number of new issues. At the same time, the model does not need to rely on the literature criticised in Lowry and Schwert (2000) to generate its predictions.

The volume and under-pricing equations can be written more generally as follows:

$$
\begin{aligned}
& N_{t}=a_{1}+\sum_{i=1}^{k} b_{1 i} \mu_{t-i}+\sum_{i=1}^{k} c_{1 i} N_{t-i}+\sum_{i=1}^{k} d_{1 i} \chi_{t-i}+\eta_{1 t} \\
& \mu_{t}=a_{2}+\sum_{i=1}^{k} b_{2 i} \mu_{t-i}+\sum_{i=1}^{k} c_{2 i} N_{t-i}+\sum_{i=1}^{k} d_{2 i} \chi_{t-i}+\eta_{2 t}
\end{aligned}
$$

where

$N_{t}$ is the number of IPOs in period t;

$\mu_{t}$ is the average under-pricing observed in period $t$;

$a, b, c$, and $d$ are parameters of the model;

$k$ is the number of lags included in the analysis;

$\chi_{t}$ is the market/economic state indicator and

the $\eta_{t}$ terms are the regression residual terms.

Thus, a simple model of supply and demand that allows for a delay in the issue of IPOs provides considerable insight into the time-series characteristics of the IPO market. The model provides one explanation for the incidence of serial correlation in both IPO volume and under-pricing. It also provides an explanation for the influence of market conditions in both under-pricing and new issue volume. Finally, the model identifies the interaction between under-pricing and IPO volume. 


\section{DATA}

The sample employed in the empirical test spans the period from January 1960 to July 2000. Data are collected on all new issues in the US market at monthly frequency. ${ }^{4}$ Of note, the level of IPO activity is restricted during the period 1973 to 1976 with fourteen months experiencing no issues. These months are dropped from the sample, yielding a final sample of 473 months. ${ }^{5}$ The average level of under-pricing per month is constructed as an equal-weighted average of first trading day under-pricing across all new issues in each month. The proxy for market conditions is measured as the monthly return on the S\&P500 index.

Descriptive statistics for the two IPO series and stock market returns are found in Panel A of Table 1. ARCH, auto-correlation and Phillips-Perron tests are reported in Panel B of Table 1. The average number of IPOs over the sample period is around 31 per month with a standard deviation of 25 issues. The average level of under-pricing per month is almost $18 \%$ over the period which is a similar figure to that reported in prior studies (see Saunders (1990) for a summary). Auto-correlation tests up to 12 lags identify strong statistically significant correlation for the IPO activity variables - both average under-pricing and the number of IPOs. This result is consistent with prior research that has demonstrated persistence in these series (Ibbotson et al. 1988, 1994). The $\mathrm{ARCH}(1)$ test and the Chi-square test for auto-correlation in the squared values verify the existence of an ARCH type process in both the number of IPOs and average under-pricing per month. Given the existence of heteroscedasticity, the Phillips-Perron

\footnotetext{
${ }^{4}$ Jay Ritter kindly supplied the data used in the analysis.
} 
test is used to examine unit roots in each time-series ${ }^{6}$ and in each case the test suggests that the series are stationary.

(Table 1 about here)

Figure 1 plots the monthly series of new issue volume and the average initial return. Cyclical behaviour in both series is evident from the graph with several large spikes in the series. The average initial return exhibits spikes in the early 1960s, late 1960s, late 1970s, early 1980s, 1991 and the late 1990s. Of note, the volume of new issues follows a similar pattern to that of the average initial return with some indication that new issue volume lags the average initial return series.

\section{EMPIRICAL RESULTS}

On initial estimation of equations (4) and (5), significant GARCH effects were found. ${ }^{7}$ As a result, to account for potential mis-specification, the model estimation was conducted in a GARCH framework using a univariate IGARCH process. ${ }^{8}$ The results from the estimation are reported in Table 2 and are based on 13 lag auto-regressions. The choice of 13 lags was based on a sequential process beginning with a maximum of 20 lags. The number of lags was progressively reduced as long as there was no evidence of serial correlation in the residuals and while the AIC and SBC criteria were

\footnotetext{
${ }^{5}$ The months dropped from the sample are December 1973, January 1974, April 1974, May 1974, July 1974 through December 1974, March through May 1975 and April 1976.

${ }^{6}$ These statistics include both a time trend and a 12 (lagged) month window for variance estimation.

${ }^{7}$ The Ljung-Box test (20 lags) statistic using the squared residuals from the number of IPOs regression was 117.85 and from the under-pricing regression was 104.91, both statistically significant.

${ }^{8}$ A GARCH(1,1) process was initially fitted to the data. The initial estimates indicated an explosive process with the GARCH parameters summing to a number slightly greater than one. Hence, restrictions are imposed through an IGARCH process.
} 
falling. ${ }^{9}$ While the choice of lag length is ultimately arbitrary, it is unlikely that the institutional features of the market would delay listing for more than 13 months. Hence, thirteen lags are included in each of the equations for each of the variables. ${ }^{10}$

(Table 2 about here)

First, we focus on the results for the volume equation (4) presented in the first column in Table 2. In such a model with a large number of regressors, caution must be placed on analysing individual coefficients. With this caveat, the individual coefficient estimates show that short lags of volume itself and recent lagged S\&P500 returns are statistically significant. Lagged under-pricing is also significant, at 5 months. ${ }^{11}$ The strength of the autocorrelation in IPO volume is evidenced by the fact that the first two lags of volume itself substantially explain current volume. This feature of strong persistence is consistent with anecdotal evidence that the new issues market gains substantial momentum. The positive impact of lagged under-pricing, at lag 5, is consistent with current under-pricing providing a signal for issuers that leads to an increased number of issues. However, it is also consistent with the impact taking some months to materialise given the institutional impediments that induce delays between the decision to issue an IPO and the actual listing date, notably within the suggested 36 month period of delay. That is, there is support for the supply argument above where it is hypothesised that issuers react to the current level of under-pricing but are constrained in their response. The statistically significant coefficient signs are positive

\footnotetext{
${ }^{9}$ Although the AIC and SBC criteria suggested a more parsimonious model there was evidence of serial correlation in the residuals once the number of lags was reduced below 13 lags.

${ }^{10}$ Moreover, the use of 13 lags allows for the possibility of seasonal effects.

${ }^{11}$ Also note that the lag at 8 months is significant at the $10 \%$ level.
} 
indicating that a rise in the current number of issues, a rise in prior under-pricing and a bullish stock market lead to an increase in the number of new issues.

Instead of analysing the individual coefficients, a more powerful test of the model is the likelihood ratio tests for joint equality to zero in the lagged parameters. These results are reported in Panel B of Table 2. For each variable in the model, the test statistics all reject the null. Panel B in Table 2 also reports the test statistics across two sub-periods of almost 20 years each created by splitting the sample in half. The full sample results hold across these sub-periods. In summary, the results in Table 2 show that current levels of under-pricing, current movements in the stock market and current volume in the IPO market all lead future new issue activity.

Turning to the under-pricing equation results reported in the second column of Table 2, the individual coefficients indicate that lagged under-pricing is statistically significant in its own series. Under-pricing is heavily influenced by its own past series, being strongly related to its own lags at one, two and four month. These results are consistent with the folklore of momentum and hot markets in IPOs.

Table 2 shows that lagged volume is not significant in the under-pricing equation, indicating that the lead-lag relationship between under-pricing and new issue volume is uni-directional. However, this conclusion is tempered by the sub-period results in Panel B that show that lagged volume yields a significant chi-square statistic, driven by the most recent sub-period. Similarly, the impact of lagged market returns are only significant in the latter sub-period, although in Panel A, the short-term lags are all positive and exhibit a relatively large coefficient value. The significant lags are around 
a year and of changing sign and we place little faith on these longer lags. Generally there is a positive relationship between past stock market performance and the level of under-pricing which is consistent with prior research (Choe et al. 1993; Rees 1997; Ibbotson and Ritter 1995).

Moreover, Busaba et al. (2001) show that underpricing is lower when investor perception of an IPO's withdrawal is more likely. Extending this conclusion, investor perceptions of the probability of withdrawal are likely to be lower in a strong stock market. Hence, underpricing is likely to be higher under these conditions, thereby inducing a positive relationship between stock market performance and the level of underpricing. The results presented here are also consistent with this argument.

\section{CONCLUSION}

Hot IPO markets are part of market folklore and there is growing evidence in the research literature to support their existence. Prior literature has generally posited a specific factor to explain the existence of hot markets with no one factor proving capable of fully accounting for the observed behaviour in either under-pricing or new issue volume measures. In this paper, we have developed a theoretical model based on both equilibrium demand and supply factors that describes under-pricing and the volume of new issues. The model was tested in the US market using monthly data over a period of 40 years.

The results reveal that the number of new issues can be characterised as having strong autocorrelation properties such that past volume leads future volume. In addition the past condition of the stock market and prior levels of under-pricing lead future new 
issue volume. The most significant lag between under-pricing and IPO volume is around 5 months, consistent with the view that firms observe the signal in current levels of under-pricing and take a decision to issue, but institutional barriers inhibit the dynamism of the response such that a delay occurs between the decision to issue and the listing date. Under-pricing itself also has strong auto-correlation properties, indicating persistence.

One plausible scenario inferred from the results is that a surge in the stock market quickly leads to increased under-pricing. As the offer price is stable close to the issue date, a rise in recent stock market prices induces greater expectations of growth and hence the occurance of under-pricing. The increase in under-pricing is seen as a signal by managers of favourable conditions. Decisions are then taken to launch a new issue, but institutional features delay the actual issue date creating an increase in the number of new issues some months later. As the new issues come onto the market at various stages, the signals are reinforced leading to apparent momentum and the creation of hot issue markets. Further, following Busaba et al. (2001), the strong stock market conditions reduce investor perceptions of withdrawal of the IPO which also increases underpricing.

In summary, this paper presents one explanation for hot issue markets. The results reported here provide insight into the dynamic nature of the IPO market. Such an understanding is critical given the importance and significant influence of this market for both firms and investors alike. 


\section{REFERENCES}

Allen, F. and Faulhaber, G.R. 1989. Signalling by Under-pricing in the IPO Market, Journal of Financial Economics 23, 303-323.

Busaba, W.Y., Benveniste, L.M. and Guo, R. (2001), The Option to Withdraw IPOs during the Premarket: Empirical analysis, Journal of Financial Economics 60, 73-102.

Choe, H., Masulis, R.W. and Nanda, V. 1993. Common Stock Offerings across the Business Cycle: Theory and Evidence, Journal of Empirical Finance 1, 3-31.

Enders, W., 1995. Applied Econometric Time-series New York: John Wiley and Sons, Inc.

Firth, M., 1997. An Analysis of the Stock Market Performance of New Issues in New Zealand, Pacific Basin Finance Journal 5, 63-86.

Helwege, J. and Liang, N. 1996. Initial Public Offerings in Hot and Cold Markets, Working paper, Federal Reserve Bank of New York.

Ibbotson, R.G. and Jaffe, J. 1975. Hot Issue Markets, Journal of Finance 30, 1027-1042.

Ibbotson, R.G. and Ritter, J. 1995. Initial Public Offerings, Handbook in Operations Research and Management Science 9, 993-1014.

Ibbotson, R.G., Sindelar, J.L. and Ritter, J. 1988. Initial Public Offerings, Journal of Applied Corporate Finance 1, 37-45.

Ibbotson, R.G., Sindelar, J. and Ritter, J. 1994. The Market's Problems with the Pricing of Initial Public Offerings, Journal of Applied Corporate Finance 7, 66-74.

James, K. and Kieschnick, R. 1997. An Analysis of Fluctuations in the US IPO Market, Working Paper, Securities and Exchange Commission of USA.

Lipman, F., 1997. Going Public Prima Publishing, USA.

Loughran, T. and Ritter, J. 1995. The New Issues Puzzle, Journal of Finance 50, 23-51.

Loughran, T. and Ritter, J. 2000. Why Don't Issuers Get Upset about Leaving Money on the Table in IPOs? Working paper, University of Florida.

Loughran, T., Ritter, J. and Rydqvist, R. 1994. Initial Public Offerings: International Insights, Pacific Basin Finance Journal 2, 165-199.

Lowry, M., 1999. Determinants of IPO Volume, Working paper, University of Rochester.

Lowry, M. and Schwert, G.W. 2000. IPO Market Cycles: Bubbles or Sequential Learning?, Working Paper, University of Rochester. 
Rajan, R. and Servaes, H. 1997. Analyst Following of Initial Public Offerings, Journal of Finance 52, 507-529.

Rees, W. 1997. The Arrival Rate of Initial Public Offers in the UK, European Financial Management 3, 45-62.

Ritter, J. 1984. The 'Hot Issue' Market of 1980, Journal of Business 57, 215-240.

Ritter, J., 1998. Initial Public Offerings, in Warren, Gorham, and Lamont Handbook of Modern Finance, D. Logue and J. Seward (eds), WGL/RIA, Boston.

Rock, K. 1986. Why New Issues are Underpriced, Journal of Financial Economics 15, 187-212.

Saunders, A. 1990. Why are so Many New Issues Underpriced? Business Review, Federal Reserve Bank of Philadelphia, March/April, 3-12.

Silberberg, E. 1981. The Structure of Economics, McGraw-Hill International Book Company, Japan. 


\section{TABLE 1 \\ SUMMARY STATISTICS OF IPO SERIES AND STOCK MARKET RETURNS}

The series examined are the number of IPOs per month (VOL), the average level of first trading day under-pricing per month (UP) and the monthly continuously compounded return on the S\&P500 (SP). Data are drawn over January 1960 to July 2000.

\begin{tabular}{|c|c|c|c|c|c|c|}
\hline $\begin{array}{l}\text { Panel A } \\
\text { Descriptive statistics }\end{array}$ & VOL & & $\mathrm{UP}(\%)$ & & $\mathrm{SP}(\%)$ & \\
\hline Mean & 30.72 & & 18.33 & & 0.78 & \\
\hline Standard deviation & 24.58 & & 21.80 & & 4.18 & \\
\hline Skewness & $0.88^{*}$ & & $1.87 *$ & & $-0.37 *$ & \\
\hline Excess kurtosis & 0.24 & & $4.30 *$ & & $-2.27 *$ & \\
\hline $\begin{array}{l}\text { Panel B } \\
\text { Time-series statistics }\end{array}$ & VOL & $(\mathrm{VOL})^{2}$ & UP & $(\mathrm{UP})^{2}$ & SP & $(\mathrm{SP})^{2}$ \\
\hline Auto-correlation & & & & & & \\
\hline Lag 1 & $0.86^{*}$ & $0.77 *$ & $0.60 *$ & $0.49^{*}$ & 0.02 & 0.05 \\
\hline Lag 2 & $0.80 *$ & $0.66^{*}$ & $0.46^{*}$ & $0.29 *$ & -0.07 & 0.08 \\
\hline Lag 3 & $0.76^{*}$ & $0.62 *$ & $0.33^{*}$ & $0.17 *$ & -0.05 & 0.08 \\
\hline Lag 4 & $0.72 *$ & $0.59 *$ & $0.34 *$ & $0.22 *$ & 0.03 & 0.05 \\
\hline Lag 5 & $0.69 *$ & $0.55 *$ & $0.29 *$ & $0.21 *$ & $0.11 *$ & -0.01 \\
\hline Lag 6 & $0.64 *$ & $0.49 *$ & $0.24 *$ & $0.19 *$ & -0.08 & 0.08 \\
\hline Lag 7 & $0.59 *$ & $0.42 *$ & $0.25^{*}$ & $0.14^{*}$ & -0.01 & 0.02 \\
\hline Lag 8 & $0.53 *$ & $0.34 *$ & $0.26 *$ & $0.21 *$ & -0.08 & -0.01 \\
\hline Lag 9 & $0.49 *$ & $0.30 *$ & $0.27 *$ & $0.22 *$ & 0.00 & 0.13 \\
\hline Lag 10 & $0.43 *$ & $0.24 *$ & $0.19 *$ & $0.13^{*}$ & -0.01 & 0.04 \\
\hline Lag 11 & $0.40^{*}$ & $0.21 *$ & $0.16^{*}$ & $0.11 *$ & -0.00 & -0.02 \\
\hline Lag 12 & $0.39 *$ & $0.21 *$ & $0.12 *$ & $0.10^{*}$ & -0.01 & -0.04 \\
\hline Chi-square test (12 lags) & $2210.70 *$ & $1315.24 *$ & $942.38 *$ & $657.63 *$ & 11.97 & 18.78 \\
\hline $\mathrm{ARCH}(1)$ test & $273.08^{*}$ & & $171.05^{*}$ & & 1.04 & \\
\hline Phillips-Perron & & & & & & \\
\hline t-statistic (12 Lags) & $-7.04 *$ & & $-10.97 *$ & & $-21.82 *$ & \\
\hline
\end{tabular}

* Significant at $5 \%$ level

Phillips-Perron tests include intercept and trend, with 12 lags for the variance estimation window and the critical value at $5 \%$ is -3.41 and at $10 \%$ is -3.12 . 


\section{TABLE 2}

\section{IGARCH ESTIMATION OF IPO MODEL}

The series examined are the number of IPOs per month, the average level of first trading day underpricing per month and the monthly continuously compounded return on the S\&P500. Data are drawn over January 1960 to July 2000. The models estimated are:

$$
\begin{aligned}
& N_{t}=a_{1}+\sum_{i=1}^{13} b_{1 i} \mu_{t-i}+\sum_{i=1}^{13} c_{1 i} N_{t-i}+\sum_{i=1}^{13} d_{1 i} \chi_{t-i}+\eta_{1 t} \\
& \mu_{t}=a_{2}+\sum_{i=1}^{13} b_{2 i} \mu_{t-i}+\sum_{i=1}^{13} c_{2 i} N_{t-i}+\sum_{i=1}^{13} d_{2 i} \chi_{t-i}+\eta_{2 t} \\
& \eta_{1,} \eta_{2 t} \sim \mathrm{N}\left(0, h_{t}\right) \\
& h_{t}=e_{0}+f_{1} \eta_{t-1}{ }^{2}+\left(1-f_{1}\right) h_{t-1}{ }^{2}
\end{aligned}
$$

where $N_{t}$ is the number of IPOs per month and $\mu_{t}$ represents the average level of under-pricing per

\begin{tabular}{|c|c|c|c|c|}
\hline \multicolumn{5}{|l|}{ Panel A - Parameter estimates } \\
\hline & \multicolumn{2}{|c|}{ Number of IPOs from (4) } & \multicolumn{2}{|c|}{ Under-pricing from (5) } \\
\hline & Parameter & t-statistic & Parameter & t-statistic \\
\hline Constant $\left(a_{1,2}\right)$ & -0.573 & -0.73 & 4.962 & $4.28^{*}$ \\
\hline \multicolumn{5}{|l|}{ Under-pricing } \\
\hline$\mu_{\mathrm{t}-1}$ & -0.004 & -0.15 & 0.419 & $6.81 *$ \\
\hline$\mu_{\mathrm{t}-2}$ & 0.014 & 0.51 & 0.231 & $3.27 *$ \\
\hline$\mu_{t-3}$ & 0.034 & 1.48 & -0.101 & -1.60 \\
\hline$\mu_{\mathrm{t}-4}$ & 0.000 & -0.01 & 0.211 & $3.45^{*}$ \\
\hline$\mu_{\mathrm{t}-5}$ & 0.064 & $2.66^{*}$ & 0.005 & 0.10 \\
\hline$\mu_{t-6}$ & 0.019 & 0.70 & -0.045 & -0.74 \\
\hline$\mu_{\mathrm{t}-7}$ & -0.015 & -0.47 & 0.060 & 1.10 \\
\hline$\mu_{\mathrm{t}-8}$ & 0.041 & 1.92 & 0.010 & 0.18 \\
\hline$\mu_{\mathrm{t}-9}$ & -0.020 & -0.76 & -0.011 & -0.21 \\
\hline$\mu_{\mathrm{t}-10}$ & -0.015 & -0.56 & 0.036 & 0.74 \\
\hline$\mu_{\mathrm{t}-11}$ & -0.009 & -0.32 & 0.033 & 0.57 \\
\hline$\mu_{t-12}$ & 0.008 & 0.26 & -0.028 & -0.53 \\
\hline$\mu_{\mathrm{t}-13}$ & -0.002 & -0.07 & -0.021 & -0.47 \\
\hline \multicolumn{5}{|l|}{ Volume } \\
\hline$N_{\mathrm{t}-1}$ & 0.539 & $9.54 *$ & -0.096 & -1.93 \\
\hline$N_{\mathrm{t}-2}$ & 0.184 & $3.24 *$ & -0.007 & -0.11 \\
\hline$N_{\mathrm{t}-3}$ & 0.014 & 0.23 & 0.020 & 0.44 \\
\hline$N_{\mathrm{t}-4}$ & 0.106 & 1.89 & 0.004 & 0.10 \\
\hline$N_{\mathrm{t}-5}$ & 0.119 & $2.26^{*}$ & -0.033 & -0.71 \\
\hline$N_{\mathrm{t}-6}$ & -0.065 & -1.13 & -0.006 & -0.11 \\
\hline$N_{\mathrm{t}-7}$ & 0.032 & 0.65 & 0.051 & 1.12 \\
\hline$N_{\mathrm{t}-8}$ & 0.008 & 0.16 & -0.059 & -1.20 \\
\hline$N_{\mathrm{t}-9}$ & -0.007 & -0.15 & 0.048 & 0.94 \\
\hline$N_{\mathrm{t}-10}$ & -0.104 & $-2.22 *$ & 0.039 & 0.83 \\
\hline
\end{tabular}
month. IGARCH is used for analysis. Chi-square tests are tests of the restriction that the stated set of parameters are jointly equal to zero. The Ljung-Box tests are for serial correlation in residuals and squared residuals. 


$\begin{array}{lrrrr}N_{\mathrm{t}-11} & 0.046 & 0.82 & 0.022 & 0.37 \\ N_{\mathrm{t}-12} & 0.108 & 2.32^{*} & -0.052 & -0.93 \\ N_{\mathrm{t}-13} & -0.058 & -1.54 & -0.004 & -0.09 \\ \text { Market returns } & & & & \\ \chi_{\mathrm{t}-1} & & & & \\ \chi_{\mathrm{t}-2} & 0.321 & 3.29^{*} & 0.130 & 1.16 \\ \chi_{\mathrm{t}-3} & 0.163 & 1.53 & 0.160 & 1.39 \\ \chi_{\mathrm{t}-4} & 0.211 & 1.88 & 0.169 & 1.40 \\ \chi_{\mathrm{t}-5} & 0.192 & 2.08^{*} & -0.035 & -0.28 \\ \chi_{\mathrm{t}-6} & 0.070 & 0.63 & 0.164 & 1.34 \\ \chi_{\mathrm{t}-7} & -0.001 & -0.01 & 0.172 & 1.19 \\ \chi_{\mathrm{t}-8} & 0.138 & 1.41 & 0.124 & 0.94 \\ \chi_{\mathrm{t}-9} & -0.042 & -0.47 & -0.035 & -0.30 \\ \chi_{\mathrm{t}-10} & -0.014 & -0.13 & 0.274 & 1.91 \\ \chi_{\mathrm{t}-11} & 0.032 & 0.37 & 0.034 & 0.25 \\ \chi_{\mathrm{t}-12} & 0.022 & 0.22 & 0.010 & 0.07 \\ \chi_{\mathrm{t}-13} & 0.029 & 0.29 & -0.304 & -2.41^{*} \\ I_{\text {IGARCH Parameters }} & -0.017 & -0.20 & 0.263 & 2.01^{*} \\ e_{1} & & & & \\ f_{2} & & & & \\ & 3.708 & 1.08 & 5.263 & 0.85 \\ & 0.337 & 5.00^{*} & 0.280 & 3.99^{*}\end{array}$

Panel B - Regression Diagnostics

Number of IPOs from (4) Under-pricing from (5)

Chi Square tests (Jan 1960 to Jul 2000)

Average monthly under-pricing

Number of IPOs per month

$\begin{array}{rr}45.50^{*} & 252.39^{*} \\ 2015.31^{*} & 26.08^{*} \\ 56.02 * & 33.13^{*}\end{array}$

S\&P500 monthly returns

$56.02 *$

$33.13^{*}$

Chi Square tests (Jan 1960 to Nov 1980)

Average monthly under-pricing

Number of IPOs per month

$47.67 * 255.50^{*}$

$3419.41^{*} \quad 16.12$

S\&P500 monthly returns

$25.23 * \quad 14.28$

Chi Square tests (Dec 1980 to Jul 2000)

Average monthly under-pricing

$48.29^{*}$

$512.45^{*}$

$185.18^{*}$

Number of IPOs per month

$65.87 *$

$37.17 *$

S\&P500 monthly returns

40.01*

Auto-correlation tests (Jan 1960 to Jul 2000)

Ljung-Box test (12 lags) residuals $\quad 11.96$

8.26

Ljung-Box test (20 lags) residuals

26.60

23.39

Ljung-Box test (12 lags) squared residuals

12.64

3.92

Ljung-Box test (20 lags) squared residuals

14.42

5.71

* Significant at $5 \%$ level

F-tests are tests of the restriction that the 13-lag term parameters are jointly equal to zero. 
Figure 1: The Relationship between Monthly IPO Volume and Average Initial Return

January 1960 - July 2000

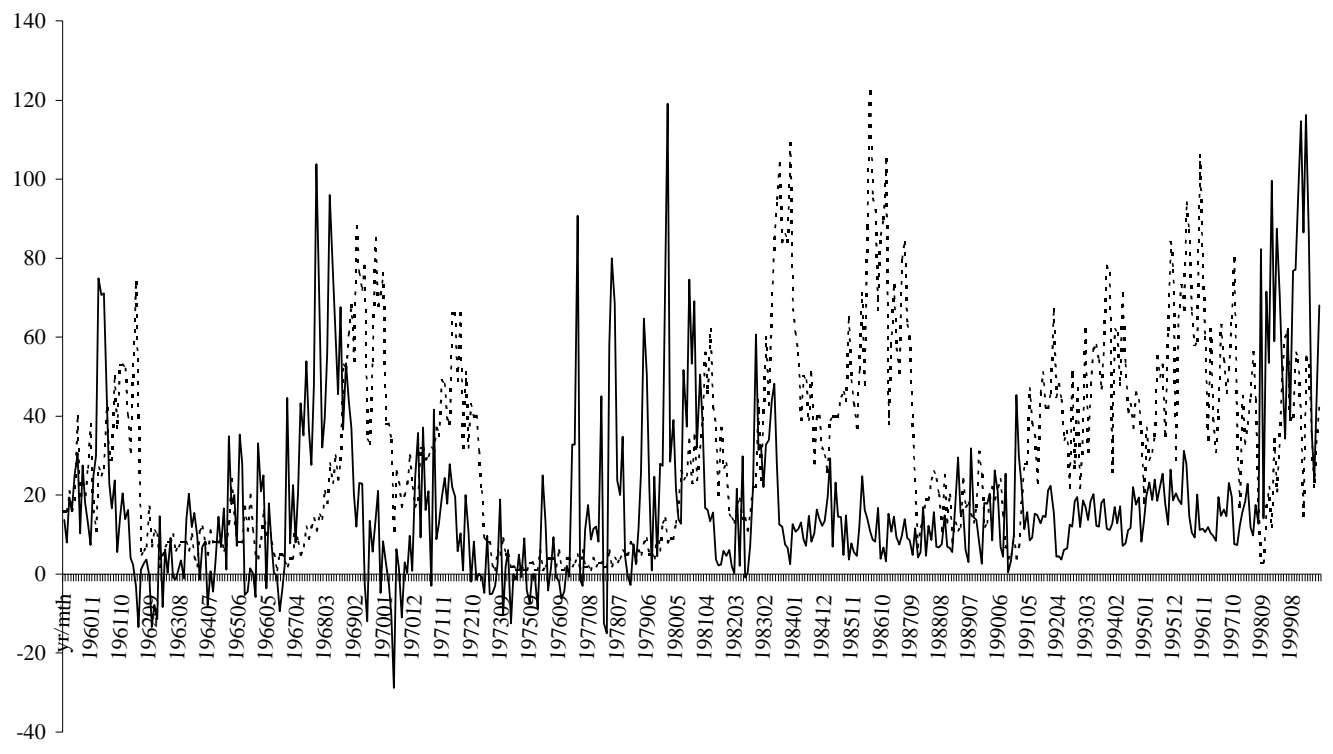

- UP $\cdots \cdot$ NOIPO 